\title{
Frequency of allogenic blood transfusion in patients with gastrointestinal cancer: a cross-sectional study in Peru
}

\author{
Jeel Moya-Salazar ${ }^{1,2}$, Eulogio Cáceres ${ }^{3}$, Jorgelina Blejer ${ }^{4}$, Carlos Gonzalez ${ }^{5}$ and Hans Contreras-Pulache ${ }^{2}$ \\ ${ }^{1}$ Pathology Department, Hospital Nacional Docente Madre-Niño San Bartolomé, Lima 15001, Peru \\ ${ }^{2}$ School of Medicine, Faculties of Health Science, Universidad Norbert Wiener, Lima 15001, Peru \\ ${ }^{3}$ Service of Blood Bank, Department of Clinical Pathology, Oncosalud, Lima 15001, Peru \\ ${ }^{4}$ Transfusion Transmissible Infections Section, Fundación Hemocentro Buenos Aires, Buenos Aires 1407, Argentina \\ ${ }^{5}$ Hemotherapy Department, Hospital de Infecciosas F.J. Muñiz, Buenos Aires 1407, Argentina
}

\section{Abstract}

Background: Gastrointestinal cancer demands a high frequency of transfusions, and the high availability of blood products. We aimed to determine the frequency of blood transfusions and the most used blood products according to the type of gastrointestinal cancer.

Methods: A cross-sectional study was conducted in a Peruvian Type I Hemotherapy and Blood Bank Service of a Private Oncological Clinic during 2016-2018. We included patients with gastrointestinal cancer using the International Code of Diseases. The donations were made in compliance with the requirements of the Programa Nacional de Hemoterapía y Banco de Sangre and in accordance with the Standardised Operational Procedure of the clinic.

Results: We analysed 3,022 patients, of which 163 (5.4\%) had gastrointestinal cancer (67.1 \pm 12 years). The 80 (49.1\%) men did not show significant differences with the $83(50.9 \%)$ women $(p=0.178)$. The most frequent neoplasia was the colon $(41.7 \%)$ and pancreas (37.4\%). Three hundred and four blood products were transfused (average $1.8 \pm 2.5$ units (range: 1-30 units/patient)), of which $81.3 \%$ (247 units) were red blood cells concentrated, 8.6\% (26 units) were fresh-frozen-plasma (FFP) and 6.6\% (20 units) were cryoprecipitate. The type of cancer that most blood products demanded was colon neoplasia (41.8\%), followed by pancreatic cancer (26.3\%) and liver cancer (10.9\%). We determined that $~ 55 \%$ of patients were $\mathrm{O} R(\mathrm{D})+$ and in five patients we were poly-transfused.

Conclusion: Our findings suggested that patients with gastrointestinal cancer require large numbers of transfusions of blood cell concentrate and FFP. Also, we showed that cancer of the colon, pancreas and liver demanded more than $75 \%$ of blood products.

Keywords: gastrointestinal cancer, transfusion, blood products, blood bank, Peru

\section{Introduction}

Following their anatomical location, the cancer of the gastrointestinal tract fluctuates between the fourth (colorectal cancer) to the fifteenth place (pancreatic cancer) of the cancers worldwide for both sexes, causing a mortality age-standardised rate of between 8.4 (8.9\%) and 4.1 (4\%) per 100,000 inhabitants [1].
Correspondence to: Hans Contreras-Pulache and Jeel Moya-Salazar.

Email: hans.contreras@uwiener.edu.pe and jeel.moyasalazar@icloud.com

ecancer 2021, 15:1289

https://doi.org/10.3332/ecancer.2021.1289

Published: $14 / 09 / 2021$

Received: 18/01/2021

Publication costs for this article were supported by ecancer (UK Charity number 1176307).

Copyright: ( $)$ the authors; licensee ecancermedicalscience. This is an Open Access article distributed under the terms of the Creative Commons Attribution License (http:// creativecommons.org/licenses/by/4.0), which permits unrestricted use, distribution, and reproduction in any medium, provided the original work is properly cited. 
Haemorrhages, intestinal perforation and obstruction are three main complications of patients with gastrointestinal cancer, due to these $\sim 25,000$ deaths arise annually in the United States (US) [2-5]. These complications demand a high availability of blood (blood products) for transfusion.

Health institutions specialised in oncology should know which blood components are more required since the oncological patient demands quality and efficiency in their Hemotherapy processes. To be exact, the institutions must emphasise the storage of the most frequent blood products and know what type of neoplasia demands greater transfusions. They must also maintain the stock of blood products to provide quality care.

In Peru, like other low-and-middle income countries, the scientific societies and health institutions do not statement the frequency, the adequate and efficient use and the availability of blood products in patients with gastrointestinal cancer [6-8]. Indeed, inadequate blood transfusion prescriptions have been reported in a National tertiary-care hospital in Lima [9].

Blood transfusions are vital for cancer patients who require these due to the problems with the tumour as well as the physiological complications and the treatment activities. However, the transfusion must be balanced against the potential benefits and risks for oncological patients [10-12].

We aimed to determine gastrointestinal cancer that requires a greater number of transfusions recorded in the blood bank service of the Oncosalud Clinic from 2016 to 2018. Moreover, we determine the most used blood products according to the type of gastrointestinal cancer.

\section{Methods}

This cross-sectional retrospective study was conducted in Type I Hemotherapy and Blood Bank Service of a Peruvian Private Oncological Clinic (TI-HBB-OncoSalud) during 2016-2018. This Service meets the internal demand of the clinic through a cooperation agreement with a Type II Blood Bank to supply blood components to oncological patients requiring transfusion. This study was approved by the Institutional Ethics Committee and the authorisation of the Heads of Departments and Services involved in the study. Further, this study complies with international guidelines for the protection of patient information.

\section{Patients' inclusion criteria and data gathering}

According to the requirements of the Clinic, we were included patients with gastric cancer was Stage I, II, III and IV (International Code of Diseases (ICD): C16.1, K92.2), pancreatic cancer (ICD: C25.0, C25.9, C25.7), liver and bile duct cancer (ICD: C22, C22.1, C22.9, C22.7, C24.0, C23.X), colon tumour (ICD: C18.2, C18.4, C18.7, C18.9, D12.5, D12.6, D12.9), anal carcinoma (ICD: C21.1) and oesophagus cancer (ICD: C15.9).

We were enrolled patients with requests for care, $\geq 18$ years, patients with preneoplastic, neoplastic or relapse and treatment control alterations and patients who had received a complete transfusion and free of complications [6, 13-15]. We consider $>4$ transfusions as high-transfusion volume. To collect the data, a previously validated form was used ( $\mathrm{a}$-Cronbach $=0.085$ ). The data were collected from the physical and electronic reports of the patients.

\section{Blood donation and transfusion}

The donations were made in compliance with the requirements of the Programa Nacional de Hemoterapía y Banco de Sangre and following the Standardised Operational Procedure (SOP) of the Blood Bank. Quadruple TERUMO bags (Shibuya, Tokyo, Japan) were used during the donation, and registered, fractionated blood products were sent in accordance with the operating needs of the clinic. The haematological values of complete blood count (CBC) of each unit were verified in the Sysmex XS-1000i Hematology Autoanalyzer (Kobe, Japan) according to the requirements of oncological patients. The transfusion was performed in compliance with the international and national guidelines for Good Practices in Blood Transfusion and the OncoSalud Clinic's SOP [10, 16]. 


\section{Data analysis}

All the data were coded from the Oncology Patients Control Notebook and the Electronic Transfusion Control System of the Clinic to the collection form and a data matrix in MS-Excel 2010 (Redmond, US) for Windows. Clinical data were included (age, sex, type of origin of neoplasm through the ICD) and laboratory data (type of blood product, CBC, etc.).

We used descriptive statistics (frequency distribution, mean and standard deviation) and non-paired T-test and chi-square considering a value of $p<0.05$ and a confidence interval of $95 \%$ as statistically significant. The statistical analysis was performed with IBM SPSS $\mathbf{2} 21.0$ (Armonk, US) and BloxPlotR (Rstudio, Tyers and Rappsilber labs, US) for Windows.

\section{Results}

Three thousand and twenty-two patients were enrolled during 2016-2018, of which 163 (5.4\%) had gastrointestinal cancer. The mean age of the patients was $67.1 \pm 12$ years $(95 \% \mathrm{Cl}$ : 65.3-68.9). The 80 (49.1\%) men did not show significant differences with the 83 (50.9\%) women $(p=0.178)$.

According to the type of neoplasia, the most frequent affectation was colon with $41.7 \%$ ( 68 patients) and pancreas with $37.4 \%$ ( 61 patients). Both the malignant tumour of the anal canal ( $2.4 \%$, four patients) and the malignant tumour of the oesophagus ( $1.2 \%$, two patients) were the least frequent. Figure 1 shows the distribution of oncologic patients according to sex and type of neoplasia.

Three hundred and four blood products were transfused to patients with gastrointestinal cancer during the study period. The $81.3 \%$ ( 247 units) were red blood cells concentrated, followed by $8.6 \%$ (26 units) of fresh-frozen-plasma (FFP) and $6.6 \%$ (20 units) of cryoprecipitate (CRYO). The type of cancer that most blood products demanded was colon neoplasia (41.8\%), followed by pancreatic cancer (26.3\%) and liver cancer (10.9\%) (Table 1). Red blood cell concentrate (RBCC) was transfused to all types of cancer, with the exception of oesophageal cancer where only 10 units of CRYO were used for each transfused patient (used mainly in surgery and in the management of pre-surgery complications).

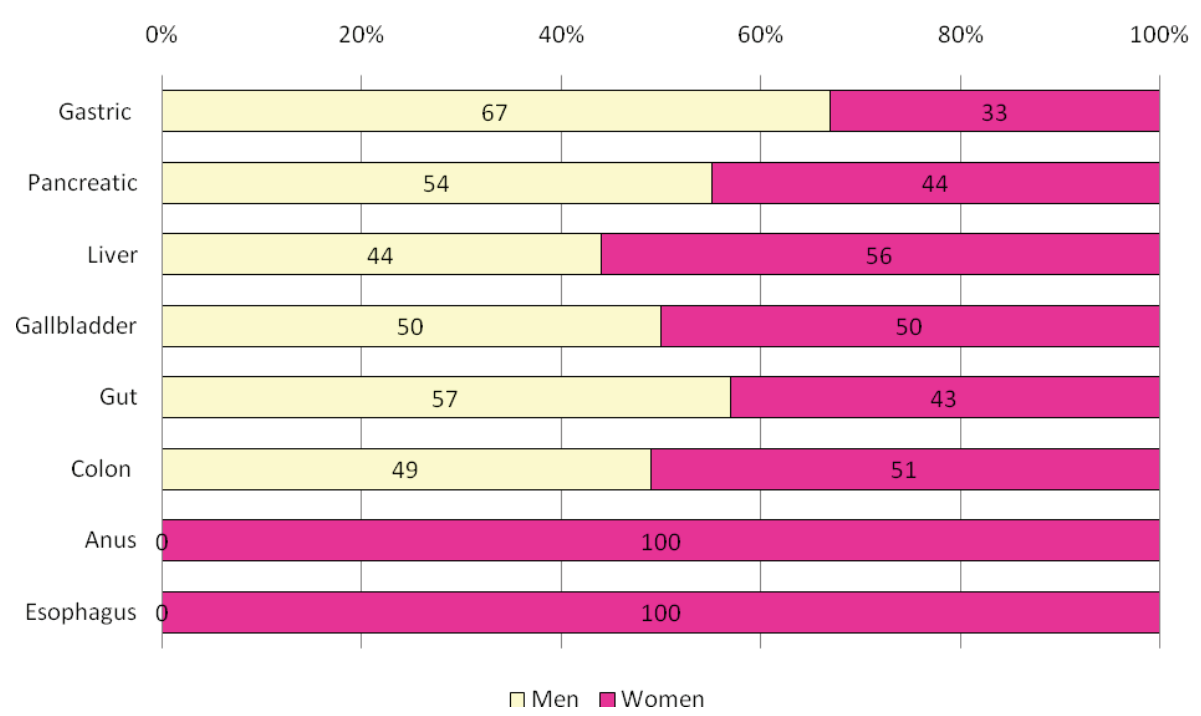

Figure 1. Distribution by sex of all Peruvian patients with a gastrointestinal cancer. We show $\sim 53 \%$ of men in patients with gastric ( $n=6$ ), pancreatic $(n=54)$, liver $(n=16)$, gallbladder $(n=6)$, gut $(n=7)$ and colon $(n=68)$. Conversely, in patients with cancer of anus $(n=4)$ and oesophagus $(n=2)$, the total of patients were women $(p=0.002)$. 
Table 1. Amount of blood products transfusing to Peruvian patients with gastrointestinal cancer $(n=163)$.

\begin{tabular}{|c|c|c|c|c|c|}
\hline \multirow{2}{*}{ Type of cancer } & \multicolumn{4}{|c|}{ Blood products } & \multirow{2}{*}{ Total } \\
\hline & RBCC & $P Q$ & FFP & CRYO & \\
\hline Gastric $(n=6)^{a}$ & $9(3)$ & $2(0.7)$ & $4(1.3)$ & $-c$ & $15(4.9)$ \\
\hline Pancreas $(n=54)$ & $75(24.7)$ & $1(0.3)$ & $4(1.3)$ & - & $80(26.3)$ \\
\hline Liver $(n=16)^{b}$ & $22(7.2)$ & $2(0.7)$ & $9(3)$ & - & 33 (10.9) \\
\hline Gallbladder $(n=6)$ & $5(1.6)$ & - & $2(0.7)$ & - & $7(2.3)$ \\
\hline Gut $(n=7)$ & $9(3)$ & $2(0.7)$ & $4(1.3)$ & - & $15(4.9)$ \\
\hline Colon $(n=68)$ & $121(39.8)$ & $4(1.3)$ & $2(0.7)$ & - & 127 (41.8) \\
\hline Anus $(n=4)$ & $6(2)$ & - & $1(0.3)$ & - & $7(2.3)$ \\
\hline Oesophagus $(n=2)$ & - & - & - & $20(6.6)$ & $20(6.6)$ \\
\hline Total & $247(81.3)$ & $11(3.6)$ & $26(8.6)$ & $20(6.6)$ & $304(100)$ \\
\hline
\end{tabular}

${ }^{\text {a }}$ Four units of RBCC and four units of FFP were transfused in one patient

${ }^{b}$ Three units of RBCC and one unit of FFP were transfused in a patient

'Not transfusedRBCC, Red blood cell concentrate; PQ, Platelets; FFP, Fresh frozen plasma; CRYO, Cryoprecipitate

In addition, the average transfusion was $1.8 \pm 2.5$ units (range: 1-30 units/patient). The maximum number of units transfused was 30 units of RBCC in a patient with colon cancer (75-year-old male, blood group O Rh(D)+ and haemoglobin $=6.2 \mathrm{gr} / \mathrm{dL}$ ) during surgical management. We determined an association between FFP with gastrointestinal cancer $(p=0.001)$ and with blood groups, $(p=0.037)$ particularly the $\mathrm{O}$ Rh (D)+ blood group.

On the clinical characteristics of patients with gastrointestinal cancer, $\sim 55 \%$ of patients were $\mathrm{O} R \mathrm{Rh}(\mathrm{D})+$ followed by blood group $A \mathrm{Rh}(\mathrm{D})+$ (35\%). In five patients, we were observed heterogeneity (poly-transfused) in the characterisation of blood groups due to previous transfusions (Figure 2). Seven (4.3\%) patients had a Rh (D) negative blood group (A and O), showing a significant difference compared to Rh (D) positive patients $(p=0.001)$.

Finally, the distributions of the origin of the patients are shown in Table 2. One hundred and three patients (63.2\%) derived from hospitalisation followed by 28 patients (17.2\%) from the Clinic's emergency area. Patients with oesophageal cancer (1.23\%) derived only from Critical Intensive Unit and Emergency, while patients with colon cancer (41.7\%), liver (9.8\%) and pancreas (33.1\%) derived from the four areas (Table 2). We did not find a significant correlation between age $(p=0.248)$, sex $(p=0.306)$ and blood group $(p=0.071)$ with blood products.

\section{Discussion}

We detected that $>78 \%$ of blood products were transfused to patients with colon, pancreas and liver cancer. These transfusions were mostly of RBCC ( 80\%), and in oesophageal cancer, the only CRYO was transfused. Our findings also suggest that more than 300 blood products were transfused in 163 patients with gastrointestinal cancer, where $>50 \%$ were men, with blood group O Rh (D)+, and from hospitalisation areas of the clinic.

The main strength of the study is that we developed the first study on the impact of allogenic blood transfusion in Peruvian patients with gastrointestinal cancer. Due to the lack of current information on this topic, we emphasise its importance and provide useful information for the management of donations/transfusion by the Blood Banks. Another important aspect is that we determine that Hospitalised area (HA) demanded the most transfusions. To best meet the blood transfusion needs and improve the service quality of the blood bank, it is necessary to know which area or department of the clinic needs more blood derivatives.

Complications in patients with the oncological disease are usually diverse. In addition to those mentioned above, there are post-surgical complications [17, 18] and metastases that certain cancers develop [19]. It has been proven for more than 35 years ago that blood transfusions can be harmful in patients with colon cancer [11, 12, 20], ovarian cancer [21], hepatocellular carcinoma [22], gastric cancer [10], amongst others. 


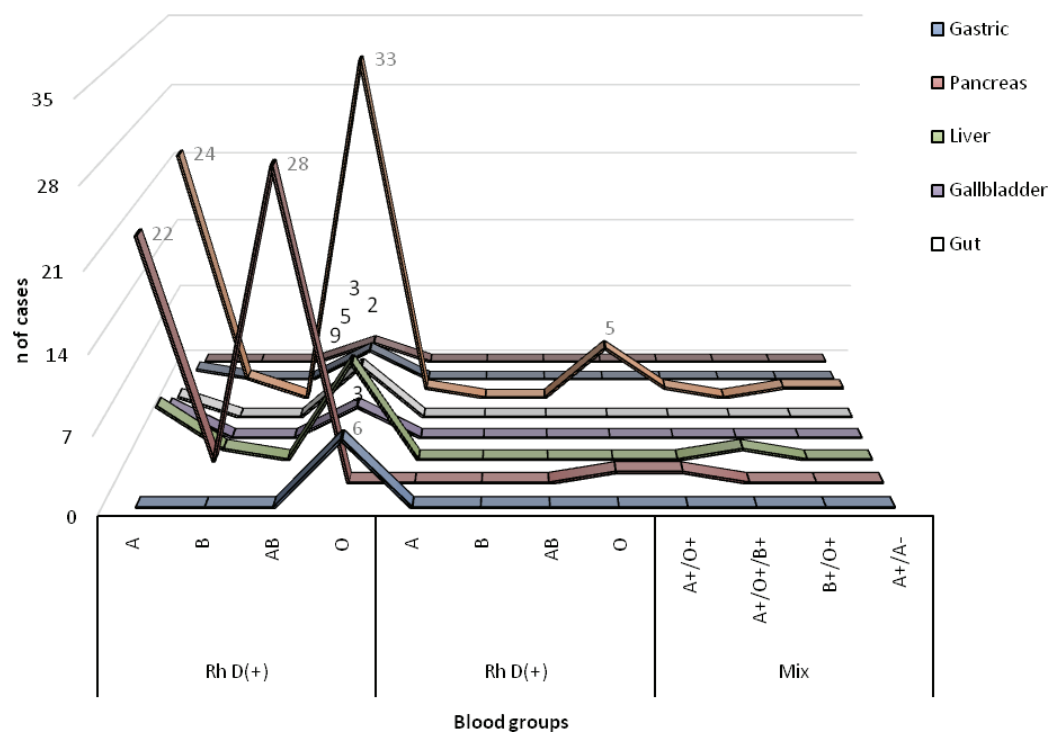

Figure 2. Blood groups of Peruvian patients with gastrointestinal cancer $(n=163)$. The blood group $\mathrm{O} h(\mathrm{D})+$ is widely distributed in all types of cancer according to the anatomical site, while the heterogeneous blood groups are only in patients with pancreas, liver and colon cancer.

Table 2. Distribution of Peruvian patients with gastrointestinal cancer according to the Clinic's place of origin of the four areas $(n=163)$.

\begin{tabular}{|c|c|c|c|c|c|}
\hline \multirow{2}{*}{ Type of cancer } & \multicolumn{4}{|c|}{ Area of provenance } & \multirow{2}{*}{ Total } \\
\hline & HA & OR & CIU & ER & \\
\hline Gastric & $1(0.61)$ & $1(0.61)$ & $4(2.45)$ & $-{ }^{a}$ & $6(3.7)$ \\
\hline Pancreas & $35(21.5)$ & $2(1.23)$ & $2(1.23)$ & $15(9.2)$ & $54(33.1)$ \\
\hline Liver & $7(4.3)$ & $7(4.3)$ & $1(0.61)$ & $1(0.61)$ & $16(9.8)$ \\
\hline Gallbladder & $3(1.8)$ & $3(1.8)$ & - & - & $6(3.7)$ \\
\hline Gut & $2(1.23)$ & $1(0.61)$ & $4(2.45)$ & - & $7(4.3)$ \\
\hline Colon & $52(31.9)$ & $4(2.45)$ & $2(1.23)$ & $10(6.13)$ & $68(41.7)$ \\
\hline Anus & $3(1.84)$ & - & - & $1(0.61)$ & $4(2.45)$ \\
\hline Oesophagus & - & - & $1(0.61)$ & $1(0.61)$ & 2 (1.23) \\
\hline Total & $103(63.2)$ & $18(11)$ & $14(8.6)$ & $28(17.2)$ & $163(100)$ \\
\hline
\end{tabular}

${ }^{a}$ Without cases

HA, Hospitalised area; OR, Operations room; CIU, Critical intensive unit; ER, Emergency

In this study, we did not register adverse effects after the transfusion. In part, the mortality rate in these patients could be due to the complications of advanced cancer and neoplastic components (i.e. immunity, nutrition), which could also be due to unjustified transfusions, as has happened in several hospitals in Lima $[9,23]$. The patients who received the most transfusions are those who have the highest risk of gastrointestinal bleeding/coagulopathies.

Recently, a Peruvian retrospective study showed that critical care areas (i.e. Critical Intensive Unit (CIU)) request more transfusions of blood products [24]. The reason for these requests was mainly due to anaemia ( $>30 \%$ ), and the most requested and transfused blood products were the red blood cells concentrated ( 60\%), followed by the FFP with $25 \%$. Our findings agree with this previous study. 
The complications of several cancers have generated high costs in the US [25]. The transfusion constitutes the medical practice to safeguard the life of the patients during the surgery, to avoid post-surgical complications and to attend the requirements that the patients with gastrointestinal cancer demand [26]. As part of the quality requirements of public and private Hemotherapy and Blood Bank centres, there is the imperative to know the needs and health realities of its users and to effectively meet all the requirements of cancer patients. Therefore, the Blood Banks must possess stocks of the most demanded blood products and a constant flow of high-quality pathogen-free donations [27].

In Peru, it has been described that $\geq 70 \%$ of the Peruvian population has group O Rh (D) +, followed by blood group $A \mathrm{Rh}(\mathrm{D})+(\geq 18 \%)$ and $\mathrm{B} R \mathrm{Rh}(\mathrm{D})+(\geq 8 \%)$ [28]. Our findings showed that the most frequent blood groups of patients with gastrointestinal cancer agree with these estimates. Likewise, the blood products most transfused were the red blood cells concentrated and the FFP (Table 1). Patients with more frequent Blood Groups receive the freshest blood or had it available versus the least frequent blood that was delayed (time) or not available.

Regardless of the type of cancer [2, 22, 29] or other diseases [30-32], the red blood cells concentrated and the FFP are the main blood products transfused worldwide. In both cases, the Blood Banks must ensure and organise the cyclical viability of these products.

This study has limitations. The first limitation is the number of patients enrolled in the study. Given the nature and period of study, we were unable to include more patients with gastrointestinal cancer who required transfusions. Second, we did not have access to the follow-up of the transfused patients; hence we could not evaluate the large post-transfusion complications of each blood product. Finally, data on patient follow-up has not been available because the patients come from different clinics in Lima (capital of Peru) and regions. By not having a standardised system, patients are lost during follow-up or are treated later in other health centres. For this reason, we were unable to know the impact of transfusions on disease-free survival, overall survival and quality of life. Further longitudinal investigation is also required to determine and differentiate transfusion adverse reactions related to blood products and neoplasia.

\section{Conclusion}

This earliest Peruvian study showed that patients with gastrointestinal cancer require a large number of transfusions of red blood cells concentrated and the FFP. Likewise, we showed that cancer of the colon, pancreas and liver demanded more than $75 \%$ of blood products.

\section{Acknowledgements}

The author acknowledges the invaluable help of Victor Rojas-Zumaran and Gonzalo Moscoso. Finally, we thank the team of Transfusion of the Peruvian OncoSalud Clinic for their support during the study.

\section{Conflicts of interest}

The authors declare that there are no conflicts of interest.

\section{Authors' contributions}

All the authors have made important intellectual contributions to this article.

\section{Funding}

The authors did not receive specific funding for this work. 


\section{References}

1. Ferlay F, Ferlay J, and Soerjomataram I, et al (2018) Global cancer statistics 2018: GLOBOCAN estimates of incidence and mortality worldwide for 36 cancers in 185 countries CA Cancer J Clin 68(6) 394-424 https://doi.org/10.3322/caac.21492 PMID: 30207593

2. Pereira J and Phan T (2004) Management of bleeding in patients with advanced cancer Oncologist 9(5) 561-570 https://doi.org/10.1634/ theoncologist.9-5-561 PMID: 15477642

3. Banaszkiewicz Z, Woda L, and Tojek K, et al (2014) Colorectal cancer with intestinal perforation - a retrospective analysis of treatment outcomes Contemp Oncol (Pozn) 18(6) 414-418

4. American Cancer Society (2018) Key statistics for colorectal cancer [https://www.cancer.org/cancer/colon-rectal-cancer/about/keystatistics.html] Date accessed: 01/17/2021

5. Kim HS, Park JS, and Lim JH, et al (2017) Surgical management of malignant bowel obstruction in recurrent pancreatic cancer Int J Surg Case Rep 32 40-42 https://doi.org/10.1016/j.ijscr.2017.01.021 PMID: 28219849 PMCID: 5318962

6. Programa Nacional de Hemoterapia y Bancos de Sangre (PRONAHEBAS) (2003) Sistema de Gestion de la Calidad del Pronahebas. Guia de Procesos (Lima: Ministerio de Salud)

7. Ministerio de Salud (MINSA) (2004) Compendio para el uso clínico de Sangre y Componentes (Lima: Programa Nacional de Hemoterapia y Bancos de Sangre)

8. Instituto Nacional Materno Perinatal (2008) Manual de Hemoterapia (Lima: Ministerio de Salud)

9. Flores-Paredes W (2011) Prescripcion inadecuada de transfusion sanguinea en un hospital de referencia de Lima, Peru Rev Peru Med Exp Salud Publ 28(4) 617-622

10. Reim D, Strobl AN, and Buchner C, et al (2016) Perioperative transfusion of leukocyte depleted blood products in gastric cancer patients negatively influences oncologic outcome. A retrospective propensity score weighted analysis on 610 curatively resected gastric cancer patients Medicine (Baltimore) 95(29) e4322 https://doi.org/10.1097/MD.0000000000004322

11. Amato A and Pescatori M (2006) Perioperative blood transfusions for the recurrence of colorectal cancer Cochrane Database Syst Rev 15 CD005033

12. Houbiers JG, van de Velde CJ, and van de Watering LM, et al (1997) Transfusion of red cells is associated with increased incidence of bacterial infection after colorectal surgery: a prospective study Transfusion 37(2) 126-134 https://doi.org/10.1046/j.15372995.1997.37297203513.x PMID: 9051085

13. Schiffer CA, Anderson KC, and Bennett CL, et al (2001) Platelet transfusion for patients with cancer: clinical practice guidelines of the American Society of Clinical Oncology J Clin Oncol 19(5) 1519-1538 https://doi.org/10.1200/JCO.2001.19.5.1519 PMID: 11230498

14. Fung MK, Eder AF, and Spitalnik SL, et al (2017) ABBB technical manual 19th edn (Bethesda: AABB)

15. Ministerio de Salud (2004) Sistema de Gestion de la Calidad del Pronahebas. Manual de Calidad. Norma Tecnica No 011-MINSA/ DGSP-V. 01 (Lima: Pronahebas)

16. Carson JL, Grossman BJ, and Kleinman S, et al (2012) Red blood cell transfusion: a clinical practice guideline from the AABB Ann Intern Med 157(1) 49-58 https://doi.org/10.7326/0003-4819-157-1-201206190-00429 PMID: 22751760

17. Andreollo NA, Lopes LR, and Coelho Neto JS (2011) Postoperative complications after total gastrectomy in the gastric cancer. Analysis of 300 patients ABCD Arq Bras Cir Dig 24(2) 126-130 https://doi.org/10.1590/S0102-67202011000200007 
18. Martos-Benitez FD, Gutierrez-Noyola A, and Echevarria-Victores A (2016) Postoperative complications and clinical outcomes among patients undergoing thoracic and gastrointestinal cancer surgery: a prospective cohort study Rev Bras Ter intensiva 28(1) 40-4 https:// doi.org/10.5935/0103-507X.20160012 PMID: 27096675 PMCID: 4828090

19. Hamamoto $\mathrm{Y}$ (2015) Complications in advanced or recurrent gastric cancer patients with peritoneal metastasis during and after palliative systemic chemotherapy Mol Clin Oncol 3(3) 539-542 https://doi.org/10.3892/mco.2015.510 PMID: 26137263 PMCID: 4471555

20. Amri R, Dinaux AM, and Leijssen LGJ, et al (2017) Do packed red blood cell transfusions really worsen oncologic outcomes in colon cancer? Surgery 162(3) 586-591 https://doi.org/10.1016/j.surg.2017.03.024 PMID: 28606725

21. Warner MLL, Dowdy SC, and Martin JR, et al (2013) The impact of perioperative packed red blood cell transfusion on survival in epithelial ovarian cancer Int J Gynaecol Cancer 23 1612-1619 https://doi.org/10.1097/01.IGC.0000436089.03581.6b

22. Yang T, Lu JH, and Lau WY, et al (2015) Perioperative blood transfusion does not influence recurrence-free and overall survivals after curative resection for hepatocellular carcinoma: a propensity score matching analysis J Hepatol 64 583-593 https://doi.org/10.1016/j. jhep.2015.10.012 PMID: 26596543

23. Solorzano BE (2004) Uso de transfusiones sanguineas y de homocomponentes en el Hospital Daniel Alcides Carrion Thesis Universidad Nacional Mayor de San Marcos, Facultad de Medicina Humana

24. Bendeze FB (2015) Características Epidemiológicas del uso clínico de Hemocomponentes Hospital Nacional Docente Madre Nino San Bartolome 2015 Thesis Universidad de San Martin de Porres, Facultad de Medicina

25. Cremieux PY, Barrett B, and Anderson K, et al (2000) Cost of outpatient blood transfusion in cancer patients J Clin Oncol 18(14) 27552761 https://doi.org/10.1200/JCO.2000.18.14.2755 PMID: 10894876

26. Goksu SS, Gunduz S, and Unal D, et al (2014) Use of blood transfusion at the end of life: does it have any effects on survival of cancer patients? Asian Pac J Cancer Prev 15(10) 4251-4254 https://doi.org/10.7314/APJCP.2014.15.10.4251 PMID: 24935379

27. Moya-Salazar J, Incio-Grande M, and Ubidia-Incio R, et al (2017) Seroprevalence, cost per donation and supply blood diminution by positive and indeterminate infectious marker in blood bank to Lima, Peru Braz J Hem Hemot 39(2) 102-107 https://doi.org/10.1016/j. bjhh.2016.11.007

28. Rhesus Negative (2018) Blood type frequencies by country including the Rh factor Rhesus Negative [http://www.rhesusnegative.net/ themission/bloodtypefrequencies/] Date accessed 01/17/2020

29. Estrin JT, Schocket L, and Kregenow R, et al (1999) A retrospective review of blood transfusions in cancer patients with anemia Oncologist 4(4) 318-324 https://doi.org/10.1634/theoncologist.4-4-318 PMID: 10476543

30. Porter J (2018) Optimal blood transfusion therapy in haemoglobinopathies thalassemia rep 8(1) 7477

31. International Society of Nephrology (2012) Chapter 4: Red cell transfusion to treat anemia in CKD Kidney Int Suppl 2(4) 311-316 https:// doi.org/10.1038/kisup.2012.36

32. Howard J (2013) The role of blood transfusion in sickle cell disease ISBT Sci Ser 8 225-228 https://doi.org/10.1111/voxs.12047 